\title{
Solid phase gene extraction isolates mRNA at high spatial and temporal resolution
}

\author{
Peter Scherp and Karl H. Hasenstein \\ BioTechniques 45:172-178 (August 2008) \\ doi $10.2144 / 000112831$
}

\begin{abstract}
Rapid, localized changes in gene expression require mRNA extraction at high temporal and spatial resolution. Current small-scale mRNA extractions depend on the removal of the cells/tissue from an organism or preserved specimens. What these methods have in common is that they are destructive and do not distinguish between genomic DNA and RNA. Therefore, extracted ( $m$ )RNA is typically contaminated by extracted cytoplasm, nuclear DNA, or other compounds, and the required purification leads to loss of especially low-abundant $m R N A$. The need to repeatedly remove mRNA from living material has led to the development of solid phase gene extraction (SPGE). SPGE sampling can be achieved using gene-specific or generic sequences and is not species-specific. Here we demonstrate the versatility and validity of this novel RNA extraction by simultaneously profiling nanos and bicoid mRNA in individual Drosophila eggs. The SPGE technique detects previously described distribution profiles of nanos and bicoid. Its low impact is underscored by the normal development of repeatedly sampled eggs. In our study, quantification of actin mRNA in germinating flax seeds linked gene expression to distinct developmental processes. These data demonstrate the universality of SPGE as a simple generic, analytical, and diagnostic procedure.
\end{abstract}

\section{INTRODUCTION}

The need to obtain genetic information from biological specimens has led to the development of sophisticated procedures such as laser capture microdissection (1), cell aspiration (2), and microfluidics (3). The interest in cell-level manipulation of mRNA is heightened by the application of atomic force microscope cantilevers modified for mRNA extraction (4) and mRNA expression (5). Using considerably less technology, solid phase gene extraction (SPGE) is rapid and can be performed in less than $2 \mathrm{~min}$ from extraction to reverse transcription. This technique minimizes contamination and does not require additional purification of the sample or removal of cells, tissue, or cytoplasm from the organism. SPGE uses glass needles that are surface-coated with oligo(-dT) or gene-specific oligonucleotide sequences. mRNA is extracted from an individual cell or tissue by direct hybridization to the probe and results in the removal of a representative mRNA sample. The sampled cells remain alive and may be sampled repeatedly at different times or locations. The hybridized mRNA is reversetranscribed and the amount of generated cDNA is sufficient for multiple real-time PCR analyses using SYBR Green or other reporter systems without pre-amplification.

To corroborate our method, we studied the mRNA extraction from Drosophila eggs and analyzed gene expression in embryonic plant roots. The distribution of nanos and bicoid mRNA in Drosophila eggs has been investigated extensively over the last decades. During oogenesis nunos and bicoid mRNA are derived from maternal nurse cells. Nanos mRNA accumulates in the posterior and bicoid mRNA accumulates in the anterior pole of the egg $(6,7)$. This distribution persists until $2 \mathrm{~h}$ after fertilization $(8,9)$. The translation of nanos and bicoid mRNA establishes protein gradients that determine the body axis and the formation of the head and abdomen (6,7).

We sampled individual eggs at four equidistant positions from anterior to posterior and simultaneously determined the absolute copy number of nanos and bicoid mRNA at the time of extraction using a SYBR Green-based (Power SYBR Green Master Mix; Applied Biosystems, Foster City, CA, USA) real-time PCR assay.

To confirm that SPGE is equally applicable to plant systems, we studied the onset of actin gene expression in germinating flax (Linum usitatissimum) seeds. Germination is initiated by imbibition and comprises radicle emergence and subsequent growth of the embryo.

Because necessary mRNAs are present in the seed $(10,11)$, plants do not require transcription for initial germination. However, transcription is essential for their subsequent growth and development (10). Actins are essential proteins and polymerize to filaments (f-actin) that control cellular processes such as vesicle trafficking (12) and cell elongation (13). The expression of actin mRNA isoforms depends on different developmental stages of the embryo during germination (14). We studied the expression of two actin genes (ACT1 and ACT2) in germinating flax roots during imbibition and early germination.

All experiments demonstrate that SPGE is ideally suited to investigate gene expression with high sensitivity. Moreover, SPGE overcomes current limitations of spatial and temporal gene expression profiling.

\section{MATERIALS AND METHODS}

\section{Extraction Probes}

Glass needles were pulled on a Sutter P-2000 micropipette puller (Sutter Instruments, Norato, CA, USA) from $1 \mathrm{~mm}$ diameter solid borosilicate glass rods (World Precision Instruments, Sarasota, FL, USA) that produced consistent tip diameters of 0.5 to $1 \mu \mathrm{m}$ as indicated by scanning electron microscopy (SEM). Coating of the needles was based on a modified protocol (15). The glass needles were incubated overnight in $30 \%$ ammonium hydroxide, rinsed with distilled water, and incubated for $30 \mathrm{~min}$ in a mixture of $1 \%$ trimethylmercaptosilane in 95\% EtOH. After silanization, the needles were rinsed in $100 \% \mathrm{EtOH}$ and dried for 2 $h$ at $150^{\circ} \mathrm{C}$.

The needles were coated by $30 \mathrm{~min}$ incubation in thiol-modified oligo$\mathrm{dT}_{10}$ nucleotides in $500 \mathrm{mM}$ sodium carbonate buffer $(\mathrm{pH} 9)$. The nanos UTR-specific sequence (5'-TCAC 
AGAAACAGACATAAAT-3'; $\mathrm{T}_{\mathrm{II}} 46.6^{\circ} \mathrm{C}$ ) was amino-linked to $1 \%$ aminopropyltrimethoxysilane-coated needles. All oligonucleotides were purchased from IDT (Coralville, IA, USA). Needles were rinsed in distilled sterile water and stored at room temperature (RT). Storage for three days resulted in no detectable decrease of efficiency.

\section{Needle Characterization}

Coating density, hybridization kinetics, and release of mRNA from the needles were tested by incubating the needles in flax poly(A) mRNA that was isolated from 2-day-old flax roots using the Straight A's mRNA Isolation kit (Novagen, Madison, WI, USA) according to the manufacturer's protocol. The mRNA was quantified ( $1 \mu \mathrm{l}$ on a Nanodrop ND-1000 spectrophotometer; NanoDrop Technologies, Wilmington, DE, USA), adjusted to $50 \mu \mathrm{g}$ $\mathrm{mRNA} \times \mathrm{mL}^{-1}$, and stored at $-20^{\circ} \mathrm{C}$. For individual experiments this mRNA stock was further diluted as indicated.

Hybridization rates were tested with probes coated in $1 \mu \mathrm{M}$ oligonucleotide and inserted in $1 \mu \mathrm{l}$ flax poly(A) mRNA for up to $100 \mathrm{~s}$. Release of needle-bound mRNA was tested by immersing individual mRNAcontaining needles in sterile, nuclease-free
A

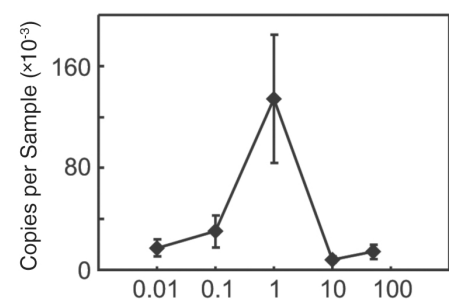

[Oligo dT] on Needle $(\mu \mathrm{M})$

B

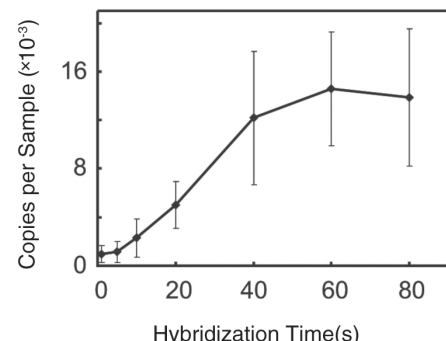

C

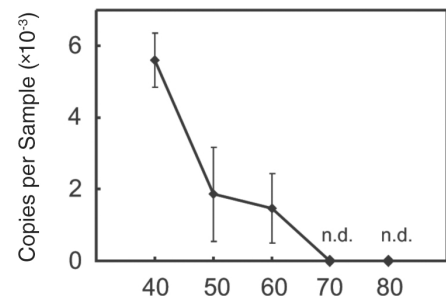

Water Temperature $\left({ }^{\circ} \mathrm{C}\right)$

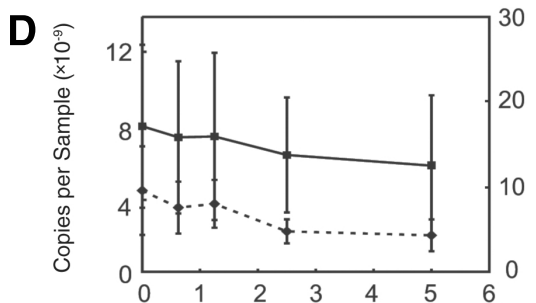

[Total HeLa RNA], ng

\section{$\mathbf{E}$}

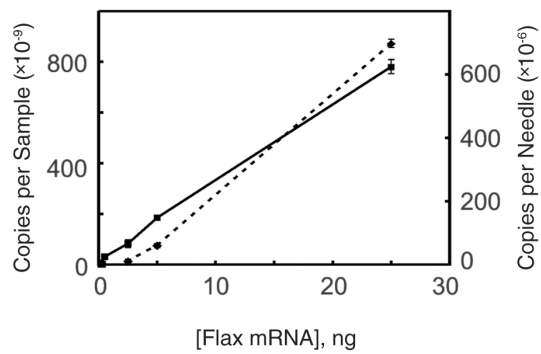

$\mathbf{F}$

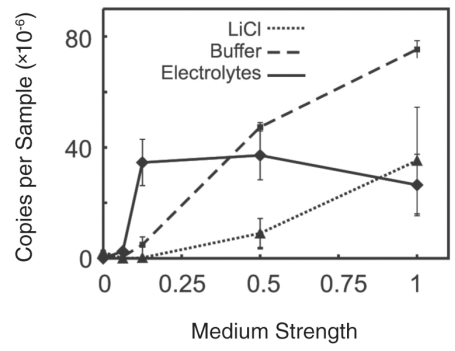

Figure 1. Determination of needle parameters. (A) Effect of oligo-d $\mathrm{T}_{10}$ coating concentration on mRNA extraction capacity. Needles coated with different concentrations of oligo-d $\mathrm{T}_{10}$ were subsequently incubated for $1 \mathrm{~min}$ in one $\mu \mathrm{l}$ flax poly(A) mRNA solution $\left(2.5 \mathrm{ng} \times \mu \mathrm{l}^{-1}\right)$, reverse-transcribed, and analyzed for $(A C T 1)$ abundance. Steric hindrance likely explains the decline at $>1 \mu \mathrm{M}$ oligo-dT. (B) mRNA hybridization was half maximal after $20 \mathrm{~s}$ and maximal after $40 \mathrm{~s}$. (C) The release of mRNA in water was a function of temperature and illustrates that mRNA was hybridized and not nonspecifically absorbed. cDNA remaining on SPGE needles was quantified after incubation ( $1 \mathrm{~min}$ ) in a reference mRNA solution and subsequent $3 \mathrm{~min}$ submersion in diethylpyrocarbonate (DEPC)-treated water at different temperatures (n.d. = not detected). (D) SPGE sampling is quantitative despite interference by competing RNA. Total flax mRNA $\left(2.5 \mathrm{ng} \times \mu \mathrm{l}^{-1}\right)$ containing the gene of interest $(A C T 1)$ was mixed with competing (HeLa) RNA $\left(0-5 \mathrm{ng}^{\circ} \mu^{-1}\right)$ such that the flax mRNA remained constant. PCR reports a constant amount of $A C T 1$ mRNA in solutions (one $\mu \mathrm{L}$, solid lines) and SPGE extractions (dashed lines). The quantity of $A C T 1$ from SPGE paralleled controls indicating that increasing amounts of competing RNA did not affect the strength of the signal. The ratio of the two lines determines the capacity of SPGE probes as equivalent to about $1 \mathrm{nl}$ of reference mRNA. (E) The reduction of the signal after dilution was equal for solution and SPGE. The hybridization of mRNA to SPGE probes was a function of ion concentration. (F) The highest amounts of mRNA were extracted in half-strength hybridization buffer, $0.075 \mathrm{M} \mathrm{LiCl}$ solution, and one-eighth strength electrolyte solution. A-C, Average from five; D-F, averages of three replicates \pm SE.

\section{DETERRENT-FREE

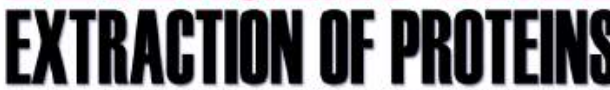

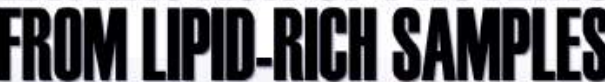

\section{ITS NOT ALWAYS WHAT YOU GET PGT Proteosolveus

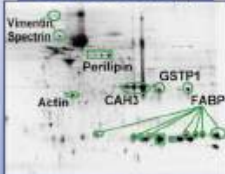 \\ PCT $9 M$ Urea, 4\% CHAPS}

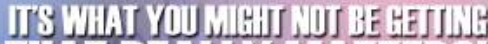

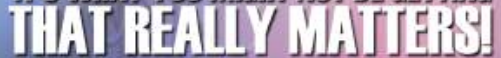

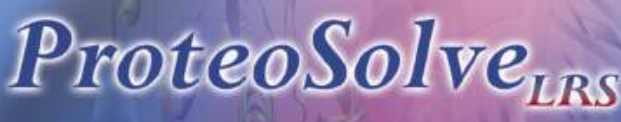




\section{Sirius}

Single Tube Luminometer

2 injectors, DLReady ${ }^{\mathrm{Tm}}$

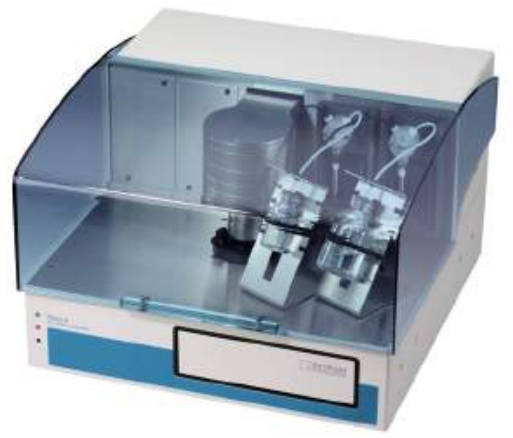

Orion II

Microplate Luminometer

4 injectors, $50^{\circ} \mathrm{C}$ incubation, 384 well, DLReady ${ }^{\mathrm{TM}}$

SENSITIVITY-Advanced photon counting for the best sensitivity.

FLEXIBILITY- Suitable for all known applications and easily adaptable to new requirements.

RELIABILITY - Quality workmanship, rigorous quality control, worldwide service and support.

VALUE - High quality instruments supplied in

a plug-and play package, at a competitive price.

Berthold Detection Systems GmbH

Bleichstrasse 56-68, D-75173 Pforzheim

Phone: $+49(0) 7231 / 9206-0$

Berthold Detection Systems USA

144 Ridgeway Square, Oak Ridge, TN 37830

Phone: 888-522-5487 (USA)

www.berthold-ds.com water of various temperatures (RT to $80^{\circ} \mathrm{C}$ ) for $3 \mathrm{~min}$.

To quantify $A C T 1$ cDNA, the hybridized needle tips were broken into PCR tubes containing reverse transcription mix I (Superscript III First Strand Synthesis System; Invitrogen, Carlsbad, CA, USA) and treated further as described below (see Reverse Transcription section and ACTI and $A C T 2$ Expression in Flax section).

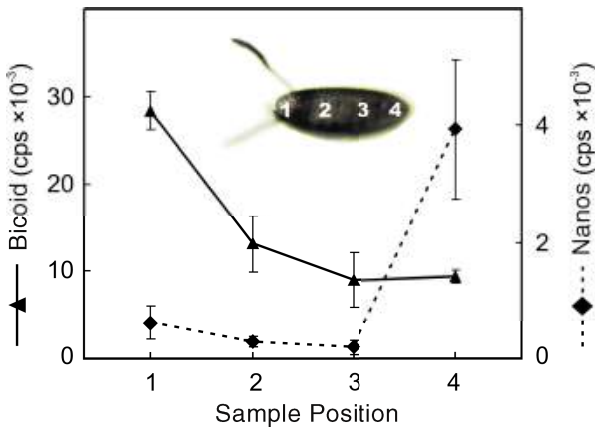

\section{Extraction Bias}

Equal amounts of flax poly(A) mRNA $\left(5 \mathrm{ng} \times \mu^{-1}\right)$ were dispensed into PCR tubes and mixed with an equal volume of serially diluted total HeLa RNA (from $10 \mathrm{ng} \times \mu^{-1}$; Superscript III First Strand Synthesis System). In a second experiment, flax poly(A) mRNA was serially diluted 1:2 $\left(25-0.25 \mathrm{ng} \times \mu \mathrm{l}^{-1}\right)$. Individual SPGE probes were incubated for $1 \mathrm{~min}$ in $1 \mu \mathrm{l}$ of each flax-HeLa RNA mixture or flax poly(A) mRNA solution. The needle-bound material was then reverse-transcribed and ACT1 cDNA was quantified using real-time PCR. For controls, one $\mu$ l of each RNA mix was reverse-transcribed and analyzed for $A C T 1$ parallel to the SPGE samples.

\section{Inductively Coupled Plasma-Optical Emission Spectrometry (ICP-OES) Analysis of Flax Root Tissue}

Flax seeds were germinated in Petri dishes on filter paper wetted with distilled water for $46 \mathrm{~h}$ at $25^{\circ} \mathrm{C}$ in the dark. Roots of 2-2.5 cm length were cut into three consecutive $5 \mathrm{~mm}$ root segments. Eighty to one hundred individual segments were pooled, dried, and weighed and extracted for $24 \mathrm{~h}$ in $3 \mathrm{~mL}$ of $70 \%$ nitric acid (trace element grade). The digested material was diluted to $12 \mathrm{~mL}$ total volume using distilled water and vacuum-filtered prior to analysis in the ICP-OES (Optima 5400 DV; Perkin Elmer, Waltham, MA, USA). The root tissue showed a composition of $13 \mathrm{mg} \mathrm{K}^{+}, 1.6 \mathrm{mg} \mathrm{Mg}^{+}$, and $0.8 \mathrm{mg} \mathrm{Ca}^{2+}$ per $\mathrm{g}$ dry weight.

A $2 \times$ stock solution $(\mathrm{pH} 7.5)$ based on this composition $\left(66 \mathrm{mM} \mathrm{K} \mathrm{K}^{+}, 13 \mathrm{mM}\right.$ $\mathrm{Mg}^{2+}$, and $4 \mathrm{mM} \mathrm{Ca}^{2+}$ ) was prepared from chloride salts of these ions and compared with hybridization buffer $(10 \mathrm{mM}$ TRIS-HCl, $0.15 \mathrm{M} \mathrm{LiCl,} 1 \mathrm{mM}$ EDTA, $0.1 \% \mathrm{SDS}, \mathrm{pH} 7.5)$ and $0.15 \mathrm{M} \mathrm{LiCl}$ solution $(\mathrm{pH} 7.5)$. These solutions were diluted with nuclease-free water and then mixed 1:1 with $25 \mathrm{ng} \times \mu \mathrm{l}^{-1}$ flax $\operatorname{poly}(\mathrm{A})$
Figure 2. Gene expression levels of nanos and $b i$ coid $\mathrm{mRNA}$ at four equidistant positions in less than 30-min-old Drosophila eggs (1-4, inset). Nanos was most abundant in the posterior of the egg (position 4) and bicoid showed reverse polarity.

mRNA before individual SPGE probes were incubated ( $1 \mathrm{~min}, 1 \mu \mathrm{L})$.

\section{SPGE of Drosophila Eggs}

Flies were grown at $25^{\circ} \mathrm{C}$ in a translucent plastic container $(50 \times 20 \times 20 \mathrm{~cm})$ and covered with a screen. Instant Drosophila medium (Ward's Natural Science, Rochester, NY, USA) was provided in 9 $\mathrm{cm}$ round Petri dishes. Eggs were collected in $5 \mathrm{~cm}$ Petri dishes containing $1.5 \%$ agar, $5 \%(\mathrm{w} / \mathrm{v})$ sucrose, $10 \%$ (w/v) corn starch, and a small yeast ball. After the desired incubation time (30 min to $4 \mathrm{~h}$ ), the Petri dish was removed and individual eggs were transferred to a microscope slide by excising the supporting agar. Under a Nikon Eclipse E600FN microscope (Nikon Instruments Melville, NY, USA) individual SPGE needles were inserted consecutively at four different positions with a micromanipulator (NMN-21; Narashige, East Meadow, NY, USA ) for $1 \mathrm{~min}$ before the tip of the needle was transferred into a PCR tube containing mix I of the reverse transcription mix.

\section{Identification of Flax $A C T 2$}

In addition to one flax actin gene obtained from GenBank (ACT1; Acc. no. AY857865), additional actins from 2-day-old flax roots were identified by amplifying cDNA with degenerate primers (16) (forward: 5'-GAYATGGAAAAGATCTGG-3'; reverse: 5'-TCYACRTCRCAYTTCATKAT-3'). The $\sim 650$ bp long PCR products obtained with this primer set were cloned (PCR-TRAP Cloning System; Genhunter, Nashville, TN, USA) and sequenced over both strands (ABI 3100; Applied Biosystems). We isolated five actin genes and chose one (named ACT2; GenBank Acc. no. DQ846903), whose protein 


\section{Research Reports}
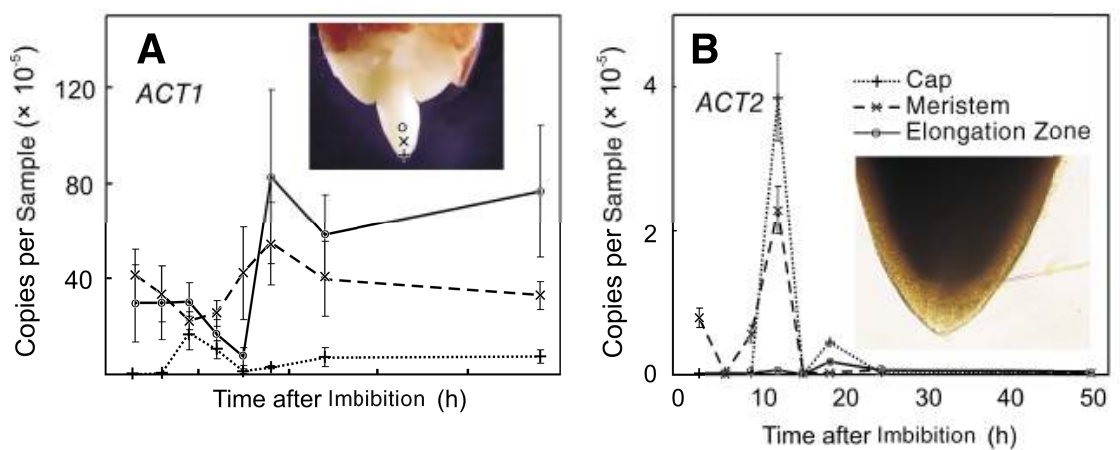

Figure 3. mRNA profile for $A C T 1$ and $A C T 2$ in the root cap, meristem, and elongation zone of embryonic flax (Linum usitatissimum) roots. (A) ACT1. Inset, root tip with sampling sites marked $\mathrm{o}, \times$, and +. (B) ACT2. Inset, tip with inserted needle. The two actin isoforms have independent expression profiles and differ between sites and germination stages. ACT1 remains permanently expressed at all three sampled locations. ACT2 peaks at the onset of mitosis (data not shown). Data shown are averages from eight replicates \pm SE.

sequence (Acc. no. ABH11670) shows high similarity to an actin protein (Acc. no. AAB40084) identified in Pyrus communis, which is related to fruit ripening.

\section{SPGE of Embryonic Flax Roots}

Flax (Linum usitatissimum) seeds were germinated on wet filter paper in a square Petri dish $(9 \times 9 \mathrm{~cm})$ and incubated vertically at $25^{\circ} \mathrm{C}$ in the dark. Every $3 \mathrm{~h}$, seeds were removed for mRNA extraction. For initial samplings (3-15 $\mathrm{h}$ after imbibition) the seed coat around the embryonic roots was removed before sampling. Seeds were positioned on an agar block and sampled at the cap, meristem, or elongation zone.

\section{Reverse Transcription}

Tubes containing one needle tip and 5 $\mu \mathrm{L}$ reverse transcription mix I (final concentration: $40 \mathrm{U}$ RNaseOUT, $1 \mu \mathrm{M}$ oligo-dT nucleotides, $10 \mathrm{mM}$ DTT) were incubated for $5 \mathrm{~min}$ at $70^{\circ} \mathrm{C}$. In a fresh PCR tube the supernatant was combined with $5 \mu \mathrm{L}$ mix II (final concentration: $1 \mathrm{mM}$ dNTP, $1 \times$ reverse transcription buffer, $5 \mathrm{mM} \mathrm{MgCl}$, and $200 \mathrm{U}$ Superscript III reverse transcriptase). Reverse transcription was carried out at $50^{\circ} \mathrm{C}$ for $50 \mathrm{~min}$. The resulting cDNA was stored at $-20^{\circ} \mathrm{C}$.

\section{External Standards for Real-time PCR}

For quantification of copy numbers, we generated cDNA standards for each investigated gene. mRNA was extracted from 10 Drosophila eggs and $102 \mathrm{~cm}$ flax root tips using the Straight A's mRNA Isolation kit (Novagen) as described in the Needle Characterization section. The mRNA from these extractions was reverse-transcribed and amplified with Amplitaq Gold polymerase
(Applied Biosystems) according to the manufacturer's protocol, using the real-time PCR primers for each gene given below. Aliquots of individual PCR products were analyzed on an agarose gel to confirm the presence of a single product. The product was purified using the Wizard SV Gel and PCR Clean-up System (Promega, Madison, WI, USA). Purified PCR products were quantified using a NanoDrop ND-1000 spectrophotometer and serially diluted (1:100). The exact quantity and known sequence of the PCR product allowed calculation of copy numbers per dilution. Each real-time PCR run contained serial dilutions of the respective genes ranging from 20 to $2 \times 10^{7}$ copies of nanos, 30 to 3 $\times 10^{7}$ copies of bicoid for Drosophila, and 130 to $1.3 \times 10^{8}$ copies of $A C T 1$ and 75 to $7.5 \times 10^{7}$ copies of $A C T 2$ for flax. Based on these standards, the copy numbers for the unknown samples were calculated by the real-time PCR software (iCycler, Bio-Rad Laboratories, Hercules, CA, USA) based on cycle threshold $\left(\mathrm{C}_{\mathrm{T}}\right)$ values. This quantification method does not compensate for variations in the reverse transcription, which contributes to the overall error.

\section{Nanos and Bicoid Expression in Drosophila Eggs}

The Drosophila cDNA was analyzed with a master mix containing final concentrations of $1 \times$ Power SYBR

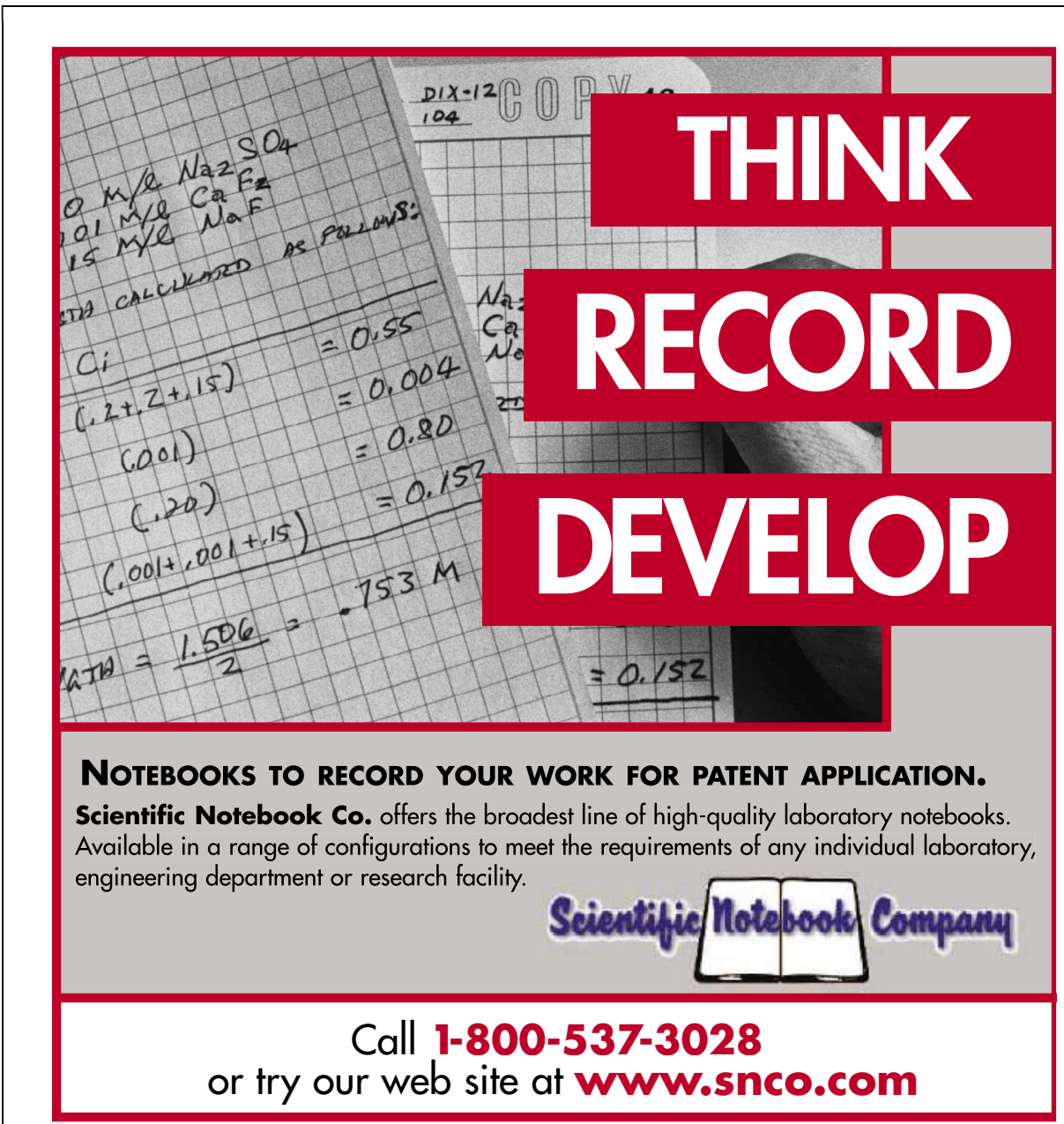




\section{Research Reports}

Green Master Mix, $200 \mathrm{nM}$ of primers for nanos (forward: 5'- TAACTTTAAC C G A G T G C T G T G C C C - 3' ; reverse: $\quad 5^{\prime}$-GCCCTCTCTAAACC TTCATCTGTTGC-3') or bicoid (forward: $5^{\prime}$-AGATCCGTGTAAATGGTTCCCAGG-3'; reverse: 5'-CCCAGATACATCTAAGGCGAATAGCG-3', all from IDT), $10 \mathrm{nM}$ fluorescein, and $1 / 10$ reaction volume of a cDNA sample. Each real-time PCR run included samples of external standards for nanos and bicoid for absolute quantification of copies per sample (cps) and normalization between different runs. All samples were run in triplicates. The correct amplification of the gene was verified by sequencing of PCR products with real-time PCR primers. Melt-curve analysis was performed after each run to assure amplification of single products.

\section{$A C T 1$ and $A C T 2$ Expression in Flax}

Multiplex real-time PCR analyses of flax $A C T 1$ and $A C T 2$ was performed using the QPCR Master Mix (ABgene, Rockford, IL, USA), $50 \mathrm{nM}$ dual-labeled probes, and $250 \mathrm{nM}$ of primers for $A C T 1$ (forward: $5^{\prime}$ CAATCTACGAAGGGTATGCTCTC-3'; reverse: 5'-CGTTGTGAACATGTACCCTCTCTC-3'; probe: 5'-FAMACGCCATTCTGCGTTT GGATCTTGCCGGTBHQ-3', BHQ = black hole quencher) and ACT2 (forward: 5'-ACGGTCA AGTCATAACCATCGG-3'; reverse: 5'-AAGTACCTGAAAGGTCCACG TC-3'; probe: 5'-HEX-TTCCAGCCCT CGATGATCGGGATGGAAGCTBHQ-3', all from IDT), 1/10 volume of cDNA, and water according to the manufacturer's protocol. SPGE samples from flax were analyzed simultaneously for ACT1 and ACT2. All experiments were run in triplicates, and copy numbers per sample were calculated from dilution series of $A C T 1$ and $A C T 2$ standards that were amplified in each run using a PCR program optimized for amplification of both genes. Separate, individual real-time PCR reactions produced the same results and showed no effect of the multiplexing on quantification. Prior to the use of the described primers and probes, the PCR products were sequenced to assure amplification of the correct gene and match of the designed dual-labeled probes.

\section{RESULTS}

\section{Needle Properties}

Initial experiments determined basic physical parameters of our needles, including various coating densities and extraction protocols in vitro. All tests, described in Figure 1, were conducted in vitro by incubation of SPGE probes in 1 $\mu \mathrm{L}$ of flax poly(A) mRNA. After this step, reverse transcription flax $A C T 1$ cDNA from individual needles was quantified as cps using a dual-labeled fluorescent probebased real-time PCR assay.

The charged nature of glass surfaces makes ionic interactions likely and might lead to unspecific binding of mRNA. Nonspecific binding to uncoated needles accounted for $0.04 \%$ of the mRNA extracted with oligo-dT-coated needles under otherwise identical conditions. In addition, incubation of the uncoated but mRNA-incubated needles in distilled water at RT resulted in no detectable signal from the needles by subsequent PCR analysis (results not shown), supporting the nonspecific nature of the mRNA:glass interaction. Maximum mRNA extraction was achieved by coating of glass needles with $1 \mu \mathrm{M}$ oligo$\mathrm{dT}_{10}$ (Figure 1A).

Hybridization was half-maximal after $10 \mathrm{~s}$ and maximum loading was achieved after $20 \mathrm{~s}$. Although longer incubation times did not increase needle loading (Figure 1B), subsequent experiments were performed with a hybridization time of $60 \mathrm{~s}$ to optimize reproducibility. The release of hybridized mRNA from the needle was temperaturedependent with no mRNA remaining at $70^{\circ} \mathrm{C}$ or higher (Figure 1C), which indicates specific mRNA-probe interaction.

Reliability of extractions and interference by unrelated RNA can be examined when constant reference mRNA is extracted and quantified in the presence of competing RNA. The amount of $A C T 1$ obtained from dilutions with competing HeLa RNA paralleled the determination with SPGE probes (Figure 1D). The ratio between the concentration of mRNA in $1 \mu \mathrm{L}$ solution and the quantity derived from SPGE probes shows a needle capacity equivalent to mRNA contained in about $1 \mathrm{~nL}$ of reference mRNA. In addition, SPGE sampling of serially diluted flax mRNA $\left(25-0.25 \mathrm{ng} \times \mu \mathrm{l}^{-1}\right)$ did not develop sample bias as indicated by the parallel slopes of dilutions (Figure 1E) and demonstrates correct representation of mRNA in SPGE extractions even at low concentrations. The linear regression of the serially diluted mRNA represents the $A C T I$ strands per ng total mRNA or the minimum poly(A) mRNA required to detect a single $A C T 1$ and thus estimates the number of $A C T 1$ per quantity of mRNA (here: one $A C T 1$ per $3.3 \times 10^{-11} \mathrm{ng}$ poly(A) mRNA).

mRNA hybridization to oligonucleotides is likely to depend on the ionic composition of the medium. We tested the impact of the ion composition based on the ion concentration found in flax roots (determined by ICP-OES), a generic mRNA hybridization buffer, and a solution of $0.15 \mathrm{M} \mathrm{LiCl}$. The ICP-OES-based solution, referred to as electrolytes, increased the extraction efficiency 22-fold in a broad range from full strength to one-eighth of in vivo concentrations. $\mathrm{LiCl}$ solution and hybridization buffer increased mRNA extraction linearly up to 63-fold (Figure 1F). Although the extraction efficiency depends on the ionic composition and strength, the endogenous conditions are adequate to assure binding of mRNA.

\section{Nanos and Bicoid Expression in Drosophila Eggs}

The spatial distribution of mRNA in $<30$-min-old Drosophila eggs was characterized by a maximum of bicoid $\mathrm{mRNA}$ at the anterior (Figure 2, position 1, $28 \times 10^{3}$ cps) and declined toward the posterior. The distributions of nanos were about fivefold higher in the posterior of the egg (Figure $2,4 \times 10^{3} \mathrm{cps}$ ) than at the other sampled locations. In contrast, in $4 \mathrm{~h}$-old eggs, bicoid was evenly distributed $\left(\sim 8 \times 10^{3} \mathrm{cps}\right.$, data not shown) but nanos retained its initial gradient. These data confirm previous reports that the bicoid mRNA gradient only exists for the first $2 \mathrm{~h}$ after oviposition (9) and corroborate previously described distributions of nanos and bicoid $(4,8)$. These experiments validate SPGE as a reliable and sensitive method for simultaneous detection of high- and low-abundant mRNA from the same sample. The low impact of SPGE sampling is perhaps best illustrated by the observation that the sampled eggs developed into normal larvae and adult flies (results not shown); this observation also indicates that SPGE sampling does not completely remove even low-abundant mRNA species. A comparison of nanos extracted with poly$\mathrm{dT}$-coated probes with a gene-specific UTR sequence showed that the yield of UTR extraction amounted to only $18.5 \%$ of the dT-coated probe. While this experiment clearly shows that gene-specific extraction is possible, the higher specificity resulted in reduced yields, possibly because of steric 


\section{Programmalole Prectision}

hindrance. However, the ratio could also represent the relative abundance between polyadenylated and UTR sequencecontaining mRNA.

Previous investigations on mRNA localization in Drosophila eggs were based on mRNA-reporter constructs such as molecular beacons (17) or injected fluorescent mRNA constructs (18). Although these methods are valuable tools for in vivo mRNA localization studies, the required genetic transformations limit these applications to single, well-characterized mRNA species. In contrast, the high spatial resolution of SPGE allows detailed mapping and quantification of any mRNA with suitable primers such as gene-specific reporters (dual-labeled fluorescent probes) or degenerate or random sequences.

\section{Actin Profiling in Germinating Flax Roots}

Because actin is often used as a housekeeping gene (19) and plays important roles in vesicle transport and cell elongation $(12,13)$, we monitored changes in the expression of two genes of this family ( $A C T 1$ and $A C T 2$ ) during the first $48 \mathrm{~h}$ of flax seed germination. ACTI mRNA showed low abundance $\left(2.1 \times 10^{4} \mathrm{cps}\right.$, Figure $\left.3 \mathrm{~A}\right)$ in the root cap $3 \mathrm{~h}$ after imbibition and peaked after $9 \mathrm{~h}\left(1.7 \times 10^{6} \mathrm{cps}\right)$ with a 40 -fold increase.

ACT1 expression was higher in the meristem and elongation zone than in the root cap. Its high abundance in the meristem $3 \mathrm{~h}$ after imbibition suggests that ACT1 mRNA is not newly synthesized. Root elongation starts $16 \mathrm{~h}$ after imbibition (20) and coincides with the onset of $A C T 1$ expression in the elongation zone (Figure 3A).

Previous reports have linked the increase in actin mRNA and protein to elongation growth in Zea mays (14) and Phaseolus vulgaris (21) but the detection of mRNA during early stages of germination was not possible because of lack of sensitivity of conventional techniques.

\section{ACT2 Expression}

Because actins belong to a large gene family, it is likely that developmental and cellular processes induce changes in expression of more than one actin isoform. The abundance of ACT2 was up to three orders of magnitude lower than $A C T 1$ levels in all examined locations. ACT2 expression peaked in the root cap and meristem $12 \mathrm{~h}$ after imbibition (Figure 3B) and coincided with the onset of mitosis (data not shown). In the elongation zone, ACT2 peaked 18 h after imbibition, similar to $A C T 1$, but its abundance was 10 - to 20 -fold lower compared with the cap or meristem. Previous reports indicate that actin isovariants are not interchangeable but have discrete functions within a specific tissue (22). Therefore, $A C T 1$ and $A C T 2$ are likely linked to specific functions during elongation growth (ACTI) and the onset of mitosis (ACT2). Our data are the first to show an increase in expression of actin (ACT2) in the meristem at the onset of mitosis and corroborate different actin expression profiles observed during seed germination in Zea mays (14) and Phaseolus vulgaris (21), but with higher sensitivity and resolution.

The copy numbers of ACT2 mRNA in the root cap (400 cps) compared to those of ACT1 mRNA $\left(8.2 \times 10^{6} \mathrm{cps}\right)$ indicate a dynamic range of 1:20,000 for low- and high-abundant genes for SPGE. The high variability in both tested actin isoforms during germination also suggests that actins are not suitable as reference genes.

The presented gene expression data were not normalized to traditional housekeeping genes. Rather we used the (uniform) oligo-dT coating on the needles to "standardize" the performed mRNA extractions. The demonstrated reproducibility of needle coating eliminates the analysis of housekeeping genes for SPGE (Figure 1) and may not need further normalization.

The combination of high sensitivity, wide dynamic range, and minimal intrusiveness makes SPGE ideally suited for analyzing mRNA at high temporal and spatial resolution. These characteristics will be useful for the assessment of gene expression and mRNA transport, storage, and longevity.

\section{DISCUSSION}

SPGE offers a novel approach to gene expression studies. We were able to extract and quantify mRNA multiple times from individual Drosophila eggs and embryonic flax roots with unprecedented spatial and temporal resolution. The spatial resolution of SPGE depends only on the tip diameter of the needle. We used probes of $0.5 \mu \mathrm{m}$ diameter; however, larger (beveled) glass tips or even stainless steel needles can be used for impaling sturdier structures. The temporal resolution is limited by the time necessary to exchange probes and by the

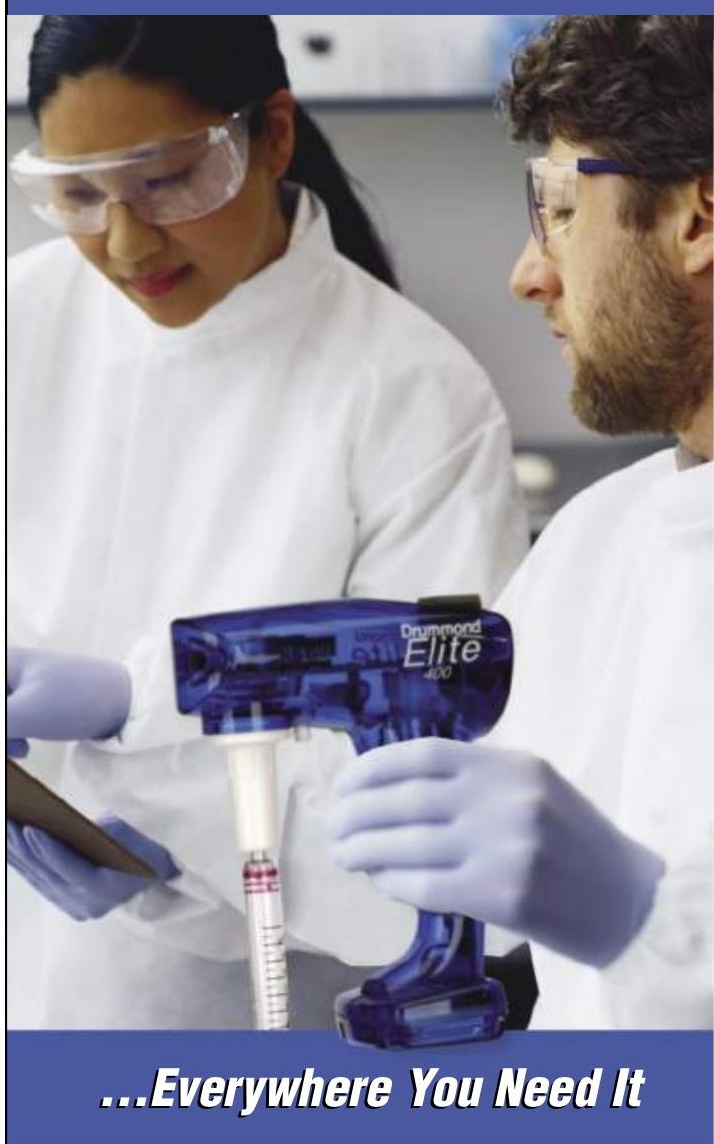

The New Portable Programmable Pipet-Aid ${ }^{\circledR}$ Elite $^{\top m}$ Provides the Fastest Way to Dispense Precise Aliquots Anywhere in the Lab

- Save time and reduce tedious prep operations

- Highly intuitive user-friendly programming functions

- Lightweight and comfortable to use with effortless

"Easy Touch" buttons and comfort pads

- Supplied complete with battery pack and charger

For high volume repetitive applications, the new Drummond Portable Programmable Pipet-Aid Elite sets an advanced standard for fast, accurate pipetting and easy comfortable operation - Provides programmable precision everywhere you need it.

\section{See the Portable Programmable Pipet-Aid $^{\circledast}$ Elite $^{\mathrm{TM}}$ in action at www.drummondsci.com}

Note: The Drummond Portable Pipet-Aid Elite is designed for use with plastic pipets up to $50 \mathrm{~mL}$ and with aqueous samples. For recommended pipet brands and a video demonstration visit our website or call us at 1-800-523-7480.

\section{DRUMMOND SCIENTIFIC COMPANY}

500 Parkway, Box 700

Broomall, PA 19008

1-800/523-7480

FAX: 1-610/353-6204

Web site: www drummondsci.com 


\section{Research Reports}

hybridization time of the mRNA to the needle-bound oligonucleotides.

Although beneficial, the use of a micromanipulator is only required for sampling of microscopic structures. Manual sampling of larger tissues allows simultaneous sampling at several positions. Despite the minute amounts of mRNA extracted, SPGE sampling is bias-free (Figure 1, D-E). The ion concentration of the sampled tissue (as shown for flax cytoplasm) is sufficient for mRNA hybridization and not a limiting factor for the efficiency of repeated extractions (Figure 1F). SPGE can be calibrated for a set of mRNAs to determine copy numbers per sample. Thus, calibrated extractions (Figure 1, D-E) allow comparisons among samples without further normalization, and they reduce but do not preclude the use of housekeeping genes.

Future experiments will examine the effectiveness of oligo-dTs of different lengths. We intend to further optimize the protocol by testing different storage conditions and the possible effect of probe hydration prior to sampling, which may affect the efficiency of our technique. However, unlike oligo-dTs, alternate (e.g., UTR) fragments are likely to differ based on the $T_{m}$ value of the sequence and their tendency to form secondary structures (loops or dimers). For this reason, the extraction efficiency of different UTR sequences must be examined individually.

The localization of mRNA within a single cell can be visualized by genetic transformation of the organism and expression of suitable reporter genes such as green fluorescent protein $(23,24)$. However, such studies require well-identified mRNA species. SPGE sampling can directly monitor the spatial distribution of any gene, for which suitable primers can be designed. Thus, SPGE can assess mRNA transport, turn-over, and sequestration.

Although extraction of mRNA from individual cells by means of oligo-dTcoated cantilevers of an atomic force microscope has been demonstrated (4), this technique requires special equipment and is limited to exposed (surface) cells and therefore is not suitable for tissue sampling. In contrast, SPGE can repeatedly sample single cells and tissue, if necessary manually. The manual sampling method offers an interesting prospect for cancer diagnoses, for example, where mRNA can be removed for genetic analysis of suspicious tissue without performing the typical biopsies. These advantages make
SPGE a universal and novel tool for gene expression studies.

\section{ACKNOWLEDGEMENTS}

This research was funded through NASA grants (nos. NAG10-0190 and NNA04CK48G).

\section{COMPETING INTEREST STATEMENT}

The method described is the subject of a U.S. patent application, "Solid Phase Gene Extraction," by Karl H. Hasenstein and Peter Scherp (Application no. 10/703,910).

\section{REFERENCES}

1. Simone, N.L., R.F. Bonner, J.W. Gillespie, M.R. Emmert-Buck, and L.A. Liotta. 1998. Laser-capture microdissection: opening the microscopic frontier to molecular analysis. Trends Genet. 14:272-276.

2. Laval, V., O.A. Koroleva, E. Murphy, C.G. Lu, J.J. Milner, M.A. Hooks, and A.D. Tomos. 2002. Distribution of actin gene isoforms in the Arabidopsis leaf measured in microsamples from intact individual cells. Planta 215:287-292.

3. Marcus, J.S., W.F. Anderson, and S.R. Quake. 2006. Microfluidic single-cell mRNA isolation and analysis. Anal. Chem. 78:3084-3089.

4. Uehara, H., T. Osada, and A. Ikai. 2004. Quantitative measurement of mRNA at different loci within an individual living cell. Ultramicroscopy 100:197-201.

5. Han, S., C. Nakamura, I. Obataya, N. Nakamura, and J. Miyake. 2005. Gene expression using an ultrathin needle enabling accurate displacement and low invasiveness. Biochem. Biophys. Res. Commun. 332:633-639.

6. Gavis, E.R. and R. Lehmann. 1992. Localization of nanos RNA controls embryonic polarity. Cell 71:301-313

7. Tautz, D. 1988. Regulation of the Drosophila segmentation gene hunchback by two maternal morphogenetic centers. Nature 332:281-284.

8. Driever, W. and C. Nüsslein-Volhard. 1988. The bicoid protein determines position in the Drosophila embryo in a concentration-dependent manner. Cell 54:95-104.

9. Surdej, P. and M. Jacobs-Lorena. 1998. Developmental regulation of bicoid mRNA stability is mediated by the first 43 nucleotides of the $3^{\prime}$ untranslated region. Mol. Cell. Biol. 18:2892-2900.

10. Rajjou, L., K. Gallardo, I. Debeaujon, J. Vandekerckhove, C. Job, and D. Job. 2004. The effect of alpha-amanitin on the Arabidopsis seed proteome highlights the distinct roles of stored and neosynthesized mRNAs during germination. Plant Physiol. 134:1598-1613.

11. Gallardo, K., C. Job, S.P.C. Groot, M. Puype, H. Demol, J. Vandekerckhove, and D. Job. 2001. Proteomic analysis of Arabidopsis seed germination and priming. Plant Physiol. 126:835-848.
12. Kim, H., M. Park, S.J. Kim, and I. Hwang. 2005. Actin filaments play a critical role in vacuolar trafficking at the Golgi complex in plant cells. Plant Cell 17:888-902.

13. Baluska, F., J. Jasik, H.G. Edelmann, T. Salajova, and D. Volkmann. 2001. Latrunculin B-induced plant dwarfism: plant cell elongation is F-actin-dependent. Dev. Biol. 231:113-124.

14. Diaz-Camino, C., R. Conde, N. Ovsenek, and M.A. Villanueva. 2005. Actin expression is induced and three isoforms are differentially expressed during germination in Zea mays. J. Exp. Bot. 56:557-565.

15. Rogers, Y.H., P. Jiang-Baucom, Z.J. Huang, V. Bogdanov, S. Anderson, and M.T. BoyceJacino. 1999. Immobilization of oligonucleotides onto a glass support via disulfide bonds: A method for preparation of DNA microarrays. Anal. Biochem. 266:23-30.

16. An, S.S., B. Mopps, K. Weber, and D. Bhattacharya. 1999. The origin and evolution of green algal and plant actins. Mol. Biol. Evol. 16:275-285

17. Bratu, D.P., B.J. Cha, M.M. Mhlanga, F.R. Kramer, and S. Tyagi. 2003. Visualizing the distribution and transport of mRNAs in living cells Proc. Natl. Acad. Sci. USA 100:13308-13313.

18. Snee, M.J., E.A. Arn, S.L. Bullock, and P.M. Macdonald. 2005. Recognition of the $b c d$ mRNA localization signal in Drosophila embryos and ovaries. Mol. Cell. Biol. 25:1501-1510.

19. Nicot, N., J.F. Hausman, L. Hoffmann, and D. Evers. 2005. Housekeeping gene selection for real-time RT-PCR normalization in potato during biotic and abiotic stress. J. Exp. Bot. 56:29072914

20. Ma, Z. and K.H. Hasenstein. 2006. The onset of gravisensitivity in the embryonic root of flax. Plant Physiol. 140:159-166.

21. Villanueva, M.A., F. Campos, C. Diáz, J.M. Colmenero-Flores, E. Dantán, F. Sánchez, and A.A. Covarrubias. 1999. Actin expression in germinating seeds of Phaseolus vulgaris $\mathrm{L}$. Planta 207:582-589.

22. Kandasamy, M.K., E.C. Mckinney, and R.B. Meagher. 2002. Functional nonequivalency of actin isovariants in Arabidopsis. Mol. Biol. Cell 13:251-261.

23. Klemenz, R., E. Frohli, R.H. Steiger, R. Schafer, and A. Aoyama. 1991. Alpha-bcrystallin is a small heat-shock protein. Proc. Natl. Acad. Sci. USA 88:3652-3656

24. Pommerrenig, B., I. Barth, M. Niedermeier, S. Kopp, J. Schmid, R.A. Dwyer, R.J. Mcnair, F. Klebl, and N. Sauer. 2006. Common plantain. A collection of expressed sequence tags from vascular tissue and a simple and efficient transformation method. Plant Physiol. 142:1427-1441.

Received 12 January 2008; accepted 6 March 2008.

Address correspondence to Karl H. Hasenstein, University of Louisiana at Lafayette, Biology Department, 300 East St. Mary Boulevard, Lafayette, LA 70504-2451, USA. e-mail: hasenstein@louisiana.edu

To purchase reprints of this article, contact: Reprints@BioTechniques.com 